\title{
Evaluation of Nuclear Grading on FNAC Smears and Tissue Sections in Carcinoma Breast
}

\author{
Dr .Noor Fatima Waris, Dr. Sabiha Maimoon, Dr. Kalpana Bothale, \\ Dr. Sadhana Mahore, \\ Professor, Department of pathology, NKPSIMS \\ Assoc Prof, Dept of Pathology, NKPSIMS \\ Prof \& Head Of Department, NKPSIMS
}

\begin{abstract}
:
Introduction: Fine needle aspiration is a very useful and widely used diagnostic tool for palpable and non palpable breast lumps. It has a sensitivity of $87 \%$ and positive predictive value of nearly $100 \%$. Nuclear grading can also be done on FNAC smears. The present study has been undertaken to correlate the morphological features of FNAC and histological grading systems. Aims and Objectives: To asses and compare cytohistomorphological nuclear grading in breast malignancies. To qualitatively estimate the nuclear grading on cytology aspiration and cytologic grading. Materials and Methods : 100 patients were studied during the period of 5 years ranging from 2005 to 2010 who presented to the Department of Surgery with an palpable breast lump. Both FNAC and histology was done. Nuclear grading system of Robinson et al was used for cytological evaluation and Eiston and Ellis modified Bloom-Richardson method was used for histological grading. Observations: Study comprised of 100 cases of duct carcinoma, 97\% of the patients diagnosed on cytology were confirmed on histological examination. There were 30 grade I tumors, 46 grade II tumors and 21 grade III tumors. Conclusions: Histological and cytological grading system were comparable to each other in predicting the grade of the tumor probability value $>0.05$. Sensitivity, specificity and accuracy were $98.9 \%$, $100 \%$ and $99 \%$ respectively.
\end{abstract}

Keywords: Breast carcinoma, cytology, histology, nuclear grading.

\section{Introduction}

The rising prevalence of breast cancer continues to concern the layman and medical fraternity. There are three main objectives for investigation in breast cancer. Firstly, to establish the correct diagnosis and stage of the disease. Secondly, to use a diagnostic modality to detect breast cancer in very early stage and thirdly to predict the outcome or prognosis ${ }^{1}$.

Fine needle aspiration is a very useful and widely used diagnostic procedure for palpable \& nonpalpable breast lumps. The preoperative diagnosis of these breast tumours by means of fine needle aspiration and followed by immunocytochemistry if required allows to choose adequate therapy ${ }^{2}$.

The present study has been designed to evaluate and compare the cytologic and histologic grading in breast malignancies, thus helping in early diagnosis and better prognosis. The increasing use of fine needle aspiration \& Cytologic grading to classify and predict the overall prognosis in these patients has resulted in varying systems and methods of evaluating the morphological details of the tumour on Fine Needle Aspirate.

Histologic grade and cytologic grade Nazoora Khan et al (2007) ${ }^{3}$.

Several histologic grading system have been developed and shown to have prognostic value in the evaluation of breast cancer.

Fisher et al (1980) have shown a 5 yr. survival of $93 \%$ for patients with good nuclear grades compared with $79 \%$ for patients with poor nuclear grades ${ }^{4}$.

Fine needle aspiration cytology of the breast is a well established method for diagnosis of breast carcinoma. It has a sensitivity of about $87 \%$ and its specificity and predictive value of a positive diagnosis is nearly $100 \%$. Rosai, (1996) ${ }^{5}$.

\section{Aim \& Objective}

- To assess and compare cytohistomorphological nuclear grading in breast malignancies.

- To qualitatively estimate the nuclear grading on cytology as a diagnostic tool for treatment in carcinoma breast patients This was a retrospective and prospective study attending the out patient of department of surgery at our hospital from June 2005 to May 2010, a period of 5 yrs. 


\section{Selection of Patients}

\section{Materials And Methods}

Patients presenting with a breast lump or mass. The study included 100 patients referred from department of surgery of our hospital. Both females and males were included in the study. Case History and Examination

A concise history was taken, followed by a thorough clinical examination with special emphasis on local examination of the breast on the lines mentioned in the proforma. Relevant investigations were carried out to aid in the diagnosis and preanaesthetic workup of the patient.

\section{Cytologic Evaluation}

The aspiration smears were examined and diagnosed according to lesion criteria outlined in the review of literature. The smears were graded employing the grading system of Robinson et al (1994) ${ }^{6}$. The grading criteria were as follows-

Table 1.1

\begin{tabular}{|c|c|c|c|}
\hline Feature & Score 1 & Score 2 & Score 3 \\
\hline Dissociation & Cells mostly in clusters & Mixture of single and cells clusters & $\begin{array}{l}\text { Cells mostly } \\
\text { single }\end{array}$ \\
\hline Cell size & $1-2 \times R B C$ size & 3-4x RBC size & $\begin{array}{l}\geq 5 \times R B C \\
\text { size }\end{array}$ \\
\hline Cell uniformity & Monomphic & Mildly pleomprohic & Pleomorphic \\
\hline Nucleoli & Indistinct & Noticeable & $\begin{array}{l}\text { Prominent } \\
\text { or } \\
\text { Pleomorphic }\end{array}$ \\
\hline Nuclear margin & Smooth & Folds & $\begin{array}{l}\text { Buds or } \\
\text { clefts }\end{array}$ \\
\hline Chromatin & Vesicular & Granular & $\begin{array}{l}\text { Clumped } \\
\text { and clear }\end{array}$ \\
\hline Grade: & $\begin{array}{l}1 \\
-14 \\
5-18\end{array}$ & & \\
\hline
\end{tabular}

\section{Histopathological Evaluation}

The tissue sections were microscopically examined and assigned diagnosis according to reviewed criteria and the sections of infiltrating ductal carcinoma were graded in the following manner using Elston and Ellis modified Bloom - Richardson method (Elston et al, 1991) ${ }^{7}$ using $0.45 \mathrm{~mm}$ diameter of microscopic field.

\section{Observation}

In the present study analysis of the data based on cytologic grading revealed the following.

1. Cell dissociation - Most of the tumours showing cell clusters belonged to grade I, while those showing clusters as well as dispersed cells belonged to grade II. Most of the tumours having dispersed cell population belonged to grade II.

2. Cell size - it was seen that most of the grade I and II tumours had cells size 2-3 times that of RBCs, while majority of Grade III tumours had cells having a size 4-5 times that of RBCs.

3. Cell uniformity - Most of the tumours with mildly pleomorphic cells belonged to grade I while most of the tumours with large pleomorphic cells belonged either to grade II or grade III.

4. Nucleoli - It was seen that most of the cases with indistinct nucleoli belonged to grade I, those with noticeable nucleoli belonged to grade II and large, prominent pleomorphic nucleoli were seen in grade III tumours.

5. Nuclear margin - It was noted that most of the cells in grade I tumours had smooth nuclear margins, while in Grade II tumours, the cells showed nuclear membrane irregularity in the form of folds. Grade III tumours also showed nuclear membrane folds in majority of the cases.

6. Chromatin detail - It was observed that most of the grade I tumours had granular chromatin. Most of the tumours of grade II and III had clumped and clear chromatin.

On summing up the above analysis, it was observed that

Most of grade I tumours had cells occurring mostly in clusters with mild pleomorphism with cell size 1-2 timess that of the erythrocytes. Their nuclei showed indistinct nucleoli, smooth nuclear margin, and granular chromatin (Fig 1).

Most of the grade II tumours showed cells in clusters as well as singly. The size of the cells was again 3-4 times that of the erythrocytes. These cells showed marked pleomorphism, noticeable nucleoli, folding of nuclear membranes and clumped clear chromatin chromatin (Fig 2).

Most of the grade III tumours had cells dispersed singly with size being more than 5 times that of the 
erythrocytes. Marked cellular pleomorphism, prominent pleomorphic nucleoli, folds in the nuclear margins and clumped and clear chromatin were seen in these tumours chromatin (Fig 3).

The present study was based on the cyto-histomorphologic evaluation of 100 cases of Carcinoma of breast. Cytologic diagnosis, grading and typing of carcinoma was carried out on aspirate smears from tumour mass. This was confirmed and correlated with histologic grading.

\section{The results and inferences derived from out study are as follows}

- The study comprised of 100 cases of duct carcinoma attending the out patient department of Surgery of our hospital.

Table 1.2: Distribution of common cases according to cytologic and histologic grades:

\begin{tabular}{|c|c|c|c|c|c|}
\hline \multirow{2}{*}{$\begin{array}{c}\text { Cytologic } \\
\text { grade (CG) }\end{array}$} & $\begin{array}{c}\text { Number of cases } \\
\text { (\%) }\end{array}$ & \multicolumn{3}{|c|}{ Histologic grade (HG) } & Concordance rate (\%) \\
\cline { 3 - 6 } & & Grade I (\%) & $\begin{array}{c}\text { Grade II } \\
\text { (\%) }\end{array}$ & $\begin{array}{c}\text { Grade III } \\
\text { (\%) }\end{array}$ & \\
\hline I & 4 & 28 & 8 & 1 & $\mathbf{9 0}$ \\
\hline II & 44 & 4 & 36 & 4 & $\mathbf{8 1 . 8 2}$ \\
\hline III & 16 & 3 & 4 & 12 & $\mathbf{8 5}$ \\
\hline Total & 100 & 31 & 48 & 17 & $\mathbf{8 4}$ \\
\hline
\end{tabular}

CH I: HG I p $>0.05$; CG II: HG $p>0.05$; CG III: HG III $p>0.05$

Breast carcinoma is the most common non-skin malignancy in females accounting for $40-50 \%$ all cancers in females WHO, (2003).

The present study was based on the cyto-histomorphologic evaluation of 100 cases of Carcinoma of breast. Cytologic diagnosis, grading and typing of carcinoma was carried out on aspirate smears from tumour mass. This was confirmed and correlated with histologic grading.

- $97 \%$ of the patient included in the study were diagnosed on cytology and confirmed on histopathology.

- Cytologic grading using Robinson's grading system was done on the 97 cases of cytologically diagnosed duct carcinoma, breast. There were 30 grade I tumours, 46 grade II tumours and 21 grade III tumours.

- The cytologic grade I tumors had mildly pleomorphic cells occurring predominantly in clusters in the smears with cell size 1-2 times that of the erthrocytes, indistinct nucleoli, smooth nuclear margins and granular chromatin.

- Most cytologic grade II tumours had smears with moderately pleomorphic cells occurring in clusters as well a singly. The cells had a size 3-4 times that of the RBCs. Their nuclei showed noticeable nucleoli, smooth nuclear membranes and coarse and granular chromatin.

- Most of cytologic grade III tumors showed singly dispersed, highly pleomorphic cells with prominent pleomorphic nucleoli, folds in nuclear margin and clumped and clear chromatin. The cell size was equal or $>5$ times that of the RBCs.

- Hisotlgoic grade I tumours had $10-75 \%$ tubule formation, moderately large pleomorpohic nuclei and $<10 \mathrm{mitosis} / \mathrm{hpf}$.

- Majority of histologic grade II tumours showed $<10 \%$ tubule formation, marked nuclear pleomorphism and $<10$ mitosis/hpf.

- Histologic and cytologic grading systems were comparable to each other in predicting the grade of the tumour ( $>0.05$ for all the three grades). Therefore, cytologic grading can be used to predict the prognosis in patients preoperatively for prognosis.

- In our study sensitivity, specificity and accuracy were $98.9 \%, 100 \%$ and $99 \%$ respectively on cytology. 


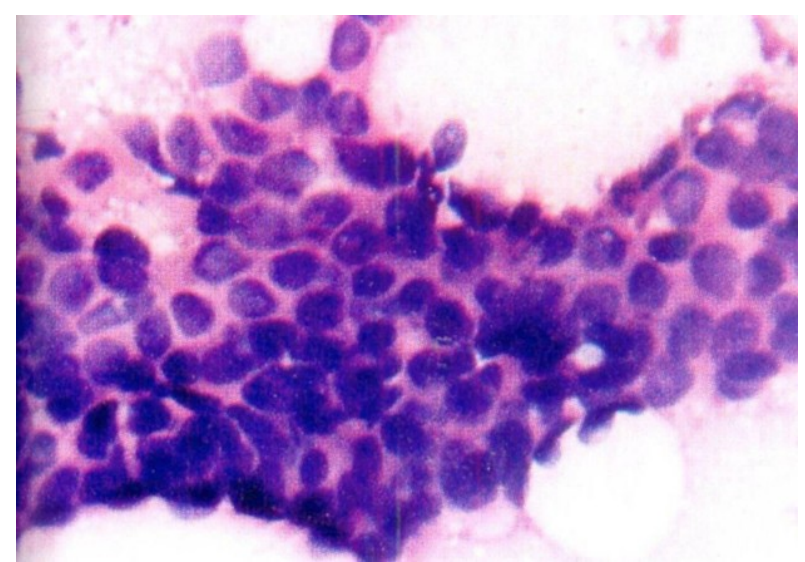

Fig 1: Photo micrograph of nuclear grade I ducts carcinoma. Loosely cohesive cluster of mild pleomorphic ductal cells with smooth nuclear margin and indistinct nucleoli

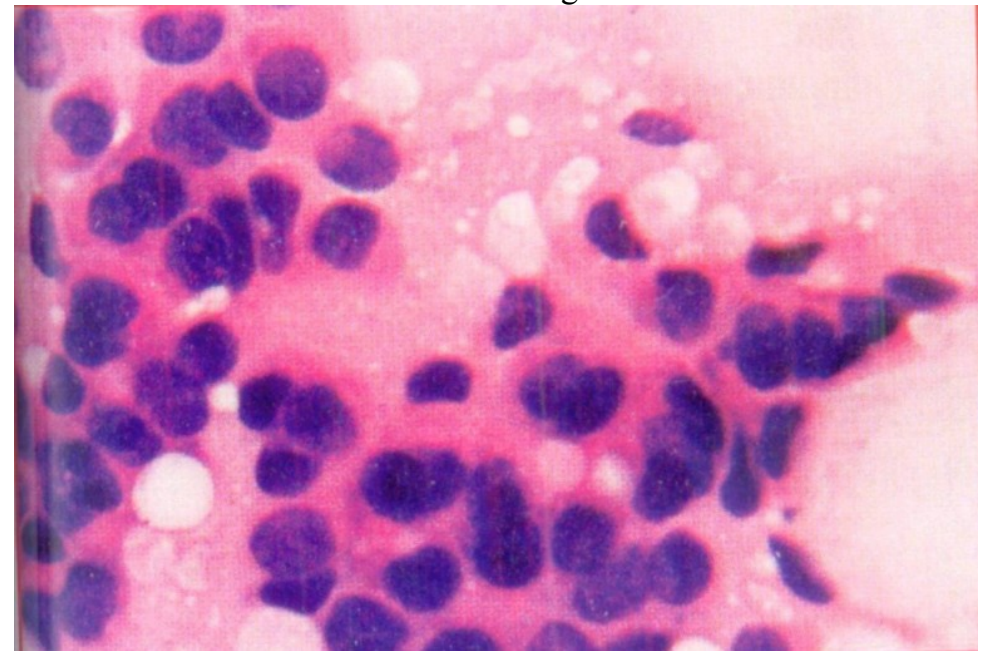

Fig 2: Photo micrograph of ductal carcinoma nuclear grade II. Tumour cells in loosely cohesive cluster and few dispersed.

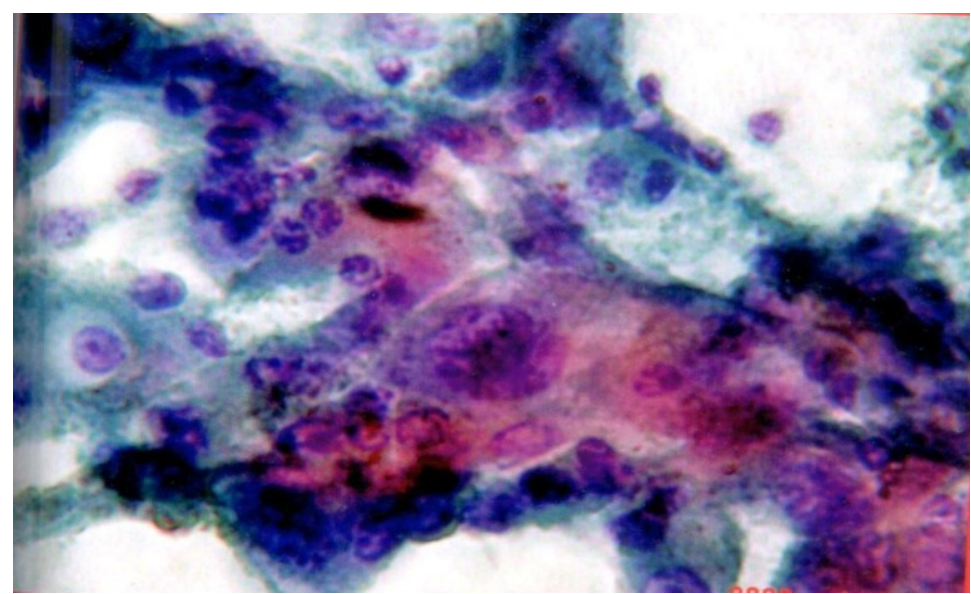

Fig 3: Photo micrograph of duct carcinoma nuclear grade III. A loosely cohesive cluster of markedly pleomorphic tumour cells more than 5 times of erythrocytes with hyperchromatic nuclei. Mildly pleomorphic nuclei with irregular nuclear margin with indistinct nucleoli and granular chromatin.

\section{Discussion}

In our study satisfactory cytologic smears were available in 97 of the 100 cases. 97 out of 100 cases were diagnosed on cytology, with histologic follow up available in 98 cases. Grading of these smears according to Robinson's Grading system Robinson et al $\mathbf{( 1 9 9 4 )}^{6}$ revealed that $30.92 \%$ tumours belonged to grade I, $47.42 \%$ to grade II and $21.64 \%$ to grade III respectively. Similar results were obtained by Frias et al (2005) ${ }^{7}$. They found $36 \%, 39 \%$ and $25 \%$ cases in grade I, II and III, respectively, employing Robinson criteria of 
cytologic grading. Chabbra et al (2005) ${ }^{9}$ using the same grading system found $30 \%, 52 \%$ and $18 \%$ cases belonging to grade I, II and III respectively.

Table 1.3: Comparison of Relative Percentage of cases in each Cytologic Grade in different studies:

\begin{tabular}{|c|c|c|c|c|}
\hline \multirow{2}{*}{\multicolumn{2}{|c|}{ Authors }} & \multicolumn{3}{|c|}{ Cytologic Grade (Percentage of Cases) } \\
\hline & & $\mathrm{I}$ & II & III \\
\hline \multicolumn{2}{|c|}{ Mouriquand \& Pasquier (1980) } & 10.04 & 37.64 & 50.59 \\
\hline \multicolumn{2}{|c|}{ Mouriquand et al (1986) } & 10.8 & 31.4 & 57.8 \\
\hline \multicolumn{2}{|c|}{ Howell et al (1994) (Scarff Bloom-Richardson Method) } & 34.29 & 48.57 & 17.14 \\
\hline \multicolumn{2}{|c|}{ Robinson et al (1994) } & 34 & 44 & 22 \\
\hline \multicolumn{2}{|c|}{ Taniquchi et al (2000) } & 31.7 & 37.5 & 31.8 \\
\hline \multirow[t]{2}{*}{ Das et al (2003) } & Robinson's Method & 28.8 & 46.2 & 25 \\
\hline & Mouriquand's Method & 9.6 & 69.2 & 21.2 \\
\hline \multicolumn{2}{|c|}{ Frias et al (2005) (Robinson's method) } & 36 & 39 & 25 \\
\hline \multicolumn{2}{|c|}{ Chhabra et al (2005) (Robinson's Method) } & 23.7 & 43 & 33.3 \\
\hline \multirow{2}{*}{\multicolumn{2}{|c|}{$\begin{array}{l}\text { Rash et al (2005) (Taniquchi's method) } \\
\text { Present Study (2004-2009) (Robinson's N }\end{array}$}} & 23.7 & 43 & 33.3 \\
\hline & & $31.63 \%$ & $48.97 \%$ & $19.50 \%$ \\
\hline
\end{tabular}

The extent of cell dissociation, appearance of nucleoli and chromatin pattern were found to be the most influential features in predicting the cytologic grade of the tumours. A study conducted by Robinson et al (1994) ${ }^{6}$ showed the extent of cell dissociation and appearance of nucleoli as the most significant features. Similar results were reported by Chhabbra et al (2005) ${ }^{9}$. They too found significant relation between the cytologic grades and the individual features (cell dissociation, appearance of nucleoli and chromatin pattern were found to be better parameters when compared to cell size, nuclear pleomorphism, and nuclear margins). Histologic grading of the sections of breast tumours was done in 98 of the 100 cases.

We employed Elston and Ellis modification of Bloom-Richardson's grading system Elston and Ellis (1991) ${ }^{7}$ to classify the tumours into three histologic grades: grade I, II and III. The study showed that $31.63 \%, 48.97 \%$ and $19.50 \%$ of cases belonged to grade I, II, \& III.

Table 1.4: Comparison of Relative Percentage of cases in each Histologic Grade in different studies:

\begin{tabular}{|c|c|c|c|}
\hline \multirow[t]{2}{*}{ Authors (year of study) } & \multicolumn{3}{|c|}{$\begin{array}{c}\text { Histologic Grade } \\
\text { (percentage of cases) }\end{array}$} \\
\hline & I & II & III \\
\hline Bloom \& Richardson (1957) & 26 & 45 & 29 \\
\hline Wolff (1966) & 33 & 33 & 34 \\
\hline Tough et al (1969) & 11 & 51 & 38 \\
\hline Champion et al (1972) & 23 & 52 & 25 \\
\hline Fisher et al (1980) & 11 & 23 & 66 \\
\hline Elston (1987) & 18 & 37 & 45 \\
\hline Contesso et al (1987) & 21 & 50 & 29 \\
\hline Robinson et al (1994) & 32 & 43 & 25 \\
\hline Antonio Robles-Frias et al (2004) & 33 & 39 & 28 \\
\hline Dash et al (2005) & 25.8 & 48.4 & 25.8 \\
\hline Present study (2004-2009) & 31.63 & 48.97 & 19.50 \\
\hline
\end{tabular}

Fisher et al (1986) $)^{10}$ and Davie et al (1986) ${ }^{11}$ in their studies have also demonstrated that, tubular differentiation and nuclear pleomorphism were the two most important histoprognostic factors to determine the prognosis.

\section{Correlation of Cytologic Grades and Histologic Grades}

On comparing the cytologic grades with the hsitolgoic grades, the difference was found to be statistically insignificant $(\mathrm{p}>0.05)$. Hence in this study the cytologic grading was comparable to histologic grading. Other authors such as Dabbs et al (1993) ${ }^{12}$; Robinson et al (1994) ${ }^{6}$; Cajulis et al (1994) ${ }^{13}$; Chhabra et al (2005) ${ }^{9}$ and Dash et al (2005) ${ }^{14}$ have also reported a statistically insignificant difference between the cytologic and histologic grades of the tumours.

In the present study 100 cases were subjected to cytology and 98 to histology, out of which 97 were diagnosed on cytology and 98 were confirmed on histopathology. Therefore in these cases cytologic and histologic grades could be compared. We noted that in these cases, the percentage of cytologic grade I, II and III tumors were $30 \%, 46 \%$ and $21 \%$, while percentage of histopathologic grade I, II, and III tumours were $31 \%$, $48 \%$ and $19 \%$ respectively. Similar findings were reported by various other authors. Also majority of the cases in this study i.e. $49 \%$, belonged to grade II which is comparable to the observations by Zoppi et al (1997) ${ }^{15}$ who recorded $57 \%$ cases in grade II and Dash et al (2005) ${ }^{14}$ who reported $43 \%$ cases belonging to grade II. On comparing each cytologic and histologic grade, insignificant difference between the two grading systems $(\mathrm{p}>0.05)$ was noted. This is in accordance with the studies of Dash et al (2005) ${ }^{14}$ and Zoppi et al (1997) ${ }^{15}$ who 
also found the two grading systems to be equally effective in classifying the tumours into three prognostic grades.

Table 1.5: Comparison of concordance rates reported in different series:

\begin{tabular}{|c|l|c|}
\hline Sr.No. & Authors & Concordance rates (in percentage) \\
\hline 1. & Howell et al (1992) & 57.1 \\
\hline 2. & Robinson et al (1994) & 56.9 \\
\hline 3. & Das et al (2003) & 71.2 \\
\hline 4. & Nijhawan et al (2003) & 82.9 \\
\hline 5. & Dash et al (2005) & 77.4 \\
\hline 6. & Chabbra et al (2005) & 65.0 \\
\hline 7. & Present study (2004-2009) & 84.0 \\
\hline
\end{tabular}

We found an overall $84 \%$ concordance rate between cytologic grade and histologic grade. Within the different grades, $90 \%$ concordance was seen in grade I, $81.82 \%$ in grade II and $75 \%$ in grade III cancers. Nijhawan et al (2003) ${ }^{16}$ reported an overall concordance between cytologic and histologic grade to be $82.9 \%$ in their study. They also reported a concordance of $90 \%$ for grade I, $85.9 \%$ for grade II, and $83.8 \%$ for grade III tumours. Our results are comparable to their reported findings. The accuracy of the grading systems by the other authors varied from 57 to $83 \%$ (Table 6.3). This variability may be due to several factors such as different systems used to assign the cytologic grades, its evaluation in air-dried materials, different staining techniques etc. The lack of correlation in the remaining $3 \%$ of cases in our study could be due to the presence of different degrees of atypia within the same tumour and the subjective value of the grading process. In addition the area of tissue sections studied might have been different from that studied in aspirated material.

In our study these sensitivity, specificity and accuracy were $\mathbf{9 8 . 9 \%}, \mathbf{1 0 0 \%}$ and $99 \%$ respectively on cytology. Study by Hemalatha et al $\mathbf{2 0 0 4}^{17}$, has similar studies showing sensitivity $85.71 \%$, specificity $100 \%$ and accuracy $96.42 \%$.

\section{References}

[1] National cancer registry programme. Consolidated report of population based cancer registries 2001; ICMR.

[2] Annual report to Nation on the status of cancer, 1973-1998, featuring cancers with recent increasing trends. J of National Cancer Institute 2001; 93(11): 824-842.

[3] Khan N, Rana F, Afroz N. Cytohistomorphological grading of breast carcinoma with special reference to apoptotic rates and lymph node metastasis. Indian J. Pathol Microbiol 2007; 50:613-618.

[4] Fisher ER, Palekar AS, Redmond C, Barton B, Fisher B: Pathologic findings from the National Surgical Adjuvant Breast Project (Protocal No. 4): VI Invasive Papillary Cancer. Am J Clin Pahtol 1980;73:313-322.

[5] Rosai J. Ackerman's Surgical Pathology, $8^{\text {th }}$ Edition, Vol. 2, Mosby Year Book Inc St. Luis: 1996; $1565-1660$.

[6] Robinson IA, McKee G, Nicholson A, D'Arcy J, Jackson PA, Cook MG, Kissin MW: Prognostic value of cytological grading of fine needle aspirates from breast carcinomas. Lancet 1994;8903: 947-949.

[7] Elston CW, Ellis IO: Pathological prognostic factors in breast cancer I. The value of histological grade in breast cancer: Ex perience from a large study with long-term follow up. Histopathology 1991;19:403-410.

[8] Frias AR, Campora RG, Parra DM, Frias MJR, Cerezuela TV, Salaverri CO, Palacin AF: Robinson cytologic grading of Invasive Ductal Breast Carcinoma-correlation with Histologic Grading and Regional Lymphnode Meqastasis. Act Cytol 2005;49:149-153.

[9] Chhabra S, Singh PK, Agarwal A, Bhagoliwal A, Singh SN: Cytological grading of breast carcinoma - A multivariate regression analysis. Journal of Cytology 2005;22:62-65.

[10] Fisher ER: Prognostic and therapeutic significance of pathological features of breast cancer. NCI Monogr 1986;1:29-34.

[11] Davies BW, Gelber D, Goldhirsh A et al: Prognostic significance of tumour grade in clinical trials of adjuvant therapy for breast cancer with axillary lymphnodes metastatis. Cancer 1986; 58:2662-2670.

[12] Dabbs DJ, Role of nuclear grading of breast carcinoma in FNA specimens. Acta Cytol 1993;37:361-366.

[13] Cajulis RS, Hessel RG, Hwang S, Haines K, Frias-Hidvegi D, O'German M: Simplified nuclear grading of the needle aspirates of breast carcinoma. Concordance with corresponding nuclear grading and flow cytometric data. Diagn Cytopathol 1994;11:124-130.

[14] Dash A, Mohanty R, Mallik R, Dash K: Aspiration smear pattern as a predictor of biological behavior in breast carcinoma. Journal of Cytology 2005;22:19-21.

[15] Zoppi J, Pellicer EM, Sundbald AS: Cytologic correlation of nuclear grade in breast carcinoma. Acta Cytol 1997;42:70 